Á. Detrich, N. Nagy, M. Nyári, E. Albert, D. Zámbó, Z. Hórvölgyi:

Nanostructured antireflective bilayers: Optical design and preparation

Materials Chemistry and Physics 145 p.176-185 (2014) 


\title{
Nanostructured Antireflective Bilayers: Optical design and Preparation
}

\author{
Ádám Detrich ${ }^{1}$, Norbert Nagy ${ }^{2}$, Mária Nyári ${ }^{1}$, Emőke Volentiru ${ }^{1}$, Dániel Zámbó ${ }^{1 \#}$, Zoltán $^{2}$ \\ Hórvölgyi ${ }^{1 *}$
}

${ }^{1}$ Budapest University of Technology and Economics, Department of Physical Chemistry and Materials Science, Centre for Colloid Chemistry, H-1521 Budapest, Hungary

${ }^{2}$ Research Centre for Natural Sciences (MTA TTK), Institute for Technical Physics and Materials Science (MFA), P. O. Box 49, H-1525 Budapest, Hungary

\#: present address: ${ }^{2}$ Research Centre for Natural Sciences (MTA TTK), Institute for Technical Physics and Materials Science (MFA), P. O. Box 49, H-1525 Budapest, Hungary

*: corresponding author. E-mail: zhorvolgyi@mail.bme.hu, Tel: + 361463 2911, Fax: + 361 4633767

Keywords: multilayers, nanostructures, coatings, sol-gel growth, visible and ultraviolet spectrometers, optical properties

\begin{abstract}
In this study we show different methods for tailoring and fabrication of various cost-effective antireflective nanocoatings for transparent as well as non-transparent substrates. The main purpose was the preparation of coatings with decreased reflectance in the full visible wavelength range by simple wet processing techniques. Structure of coatings was designed by optical simulations applying simplified calculations considering the refractive index of substrates and aiming the broadband antireflective properties. The advantageous optical properties were achieved by bilayered structures combining compact and porous sol-gel derived oxide layers utilizing molecular templating as well as nanoparticulate films. The applied bilayered structures enhance the flexibility of design by not only the selection of the layer thicknesses but also by different ways of adjusting the effective refractive index of the layers. Furthermore, chemical stability of the coatings was also investigated. The optical and structural properties of prepared films and bilayered coatings were studied by UV-vis spectroscopy and scanning electron microscopy, respectively. The transmittance of coated glass substrates is above $97.5 \%$, the reflectance of coated silicon substrates is less than $4 \%$ between $450 \mathrm{~nm}$ and $900 \mathrm{~nm}$.
\end{abstract}




\section{Introduction}

Nanosized materials are in the focus of scientific interest because of their special properties in many areas (e.g. catalysis, microelectronics, protection of the environment, biomedical applications). Consciously influencing materials at the atomic, molecular or nanoscale can result in species with the desired structure, characteristics and suitability for many practical applications. Nanostructures can be developed in various forms (coatings, nanoparticles, mesoporous gels etc.) depending on the actual purposes.

For the formation of nanostructured coatings sol-gel method [1] is widely used which includes many layer deposition techniques (e.g. dip coating, spin coating, doctor blading). For creating uniform coatings on large surfaces dip coating is probably the most effective technique. Applying this method a precursor sol is synthesized first in which controlled hydrolysis and polycondensation of various alkoxydes take place. After layer deposition coatings are generally annealed at elevated temperature developing a well defined, mechanically stable thin layer. Porous structures also can be formed by doping the precursor sols with thermally sensitive materials which form regular supramolecular units (e.g. micelles, polymer chains) during layer deposition and are eliminated at high temperature. For such purposes various surfactants or polymers can be used. Structure and size of pores and value for porosity can be controlled by changing the molecular build up and amount of the dopant [2-5].

Optimizing the parameters of such thin layers (mostly their effective refractive index and thickness) coatings can be developed with advantageous optical properties which make them suitable for application in eyeglasses, solar cells and other optical or optoelectronic devices [6-14]. Possibilities for finer tuning of the optical properties can be broadened by the creation of layers with graded refractive index and bi- or multilayered structures [15-17]. Such multilayered systems can provide additional functionality for the coating aside the advantageous optical properties (e.g. coatings with antireflective and photocatalytic [18] or antireflective and superhydrophobic [19] characteristics).

One of the greatest challenges by the formation of a coating with desired optical properties is the adjusting of the appropriate refractive index and layer thickness values. The main problem is that bulk refractive index of most materials is higher than the desired value. Formation of a layer with voids or pores (results in lower effective refractive index) can provide solution for this question. Hexagonally close packed array of spherical nanoparticles prepared by various methods (e.g. Langmuir - Blodgett (LB) [20-27], convective assembly process [28]) and micro- or mesoporous sol-gel films are typical examples for the realization of such structures. Furthermore omnidirectional antireflective coatings based on spherical or hemispherical structures also can be prepared [29-30].

In this study we present methods and significant examples for optical tailoring, preparation and optical characterization of bilayered antireflective coatings on transparent (glass) and non-transparent (silicon) substrates using various fabrication methods. On glass a compact silica sol-gel film was covered by a close packed array of spherical Stöber silica nanoparticles deposited by the LB technique. On silicon substrate a titania layer and a porous silica sol-gel film were stratified onto each other by dip coating. These types of layers were chosen because of their refractive indices make them suitable for developing antireflective structures. Thickness values were calculated by optical simulations for both systems. Optical investigation of the prepared coatings was carried out by UV-vis spectroscopy taking transmittance or reflectance spectra of the coatings on glass or silicon substrates, respectively. 


\section{Theoretical Considerations and Experimental Details}

\subsection{Optical design of antireflective coatings}

Design of antireflective coatings was carried out by applying the basic principles of thin layer optics. The general purpose was minimizing the reflectance of visible light in the broadest possible wavelength range. For the determination of the appropriate refractive index and layer thickness the following conditions were used (see Eqs. 1-2. [6-9]):

$$
\begin{aligned}
& d=\frac{\lambda_{\max }}{4 n_{e f f}} \\
& n_{e f f}=\sqrt{n_{1} n_{2}} .
\end{aligned}
$$

Eq. 1. is the so called " $\lambda / 4$ condition" ( $d$ and $n_{\text {eff }}$ are the thickness and the effective refractive index of the layer, respectively and $\lambda_{\max }$ is the wavelength corresponds to the lowest reflectance). In Eq. 2. $\mathrm{n}_{1}$ and $\mathrm{n}_{2}$ are refractive indices for the media between which the layer can be found (e.g. in case of a monolayer 1 and 2 corresponds to the substrate and the surrounding medium, respectively). For finer tuning of the parameters transmittance or reflectance spectra were simulated considering the supposed structure of the layer.

Wavelength range of low reflectance can be broadened by developing a refractive index gradient through the coating which can be carried out by the preparation of bilayers. Optimal refractive index and thickness values can be assumed also by applying simulations.

In this work we prepared antireflective coatings on transparent (glass) and non-transparent (silicon) substrates with basically different refractive indices ( $c a .1 .52$ for glass and 3.88 [31] for silicon, respectively). From this reason different types of layers were required which cover a quite wide range of refractive indices for the preparation of coatings: compact (cSiSG) and porous (pSiSG) silica sol-gel films, titania (TiSG) sol-gel films and LB layers of Stöber silica nanoparticles were used. Refractive index values for the simulations were taken from the literature or from our previous experimental data. Transmittance or reflectance spectra of monolayers were simulated with a model supposed a homogeneous monolayer on the substrate [32]. Structure of bilayered coatings was approximated with two optically homogeneous layers on each other $[8,32-33]$. Simulations were used for assuming the appropriate layer thickness values and coatings were prepared according to the calculated optimal parameters.

\subsubsection{Antireflective coatings for transparent substrates}

Glass was used for the experiments as transparent substrate with a refractive index of $c a$. 1.52. In this case a layer with an effective refractive index of 1.23 can provide perfect antireflective property at a given wavelength (see Eq. 2.). Hexagonally close packed array of spherical Stöber silica nanoparticles has a value of $c a$. 1.25 (it was calculated using the Lorentz-Lorenz [34-36] effective medium approximation [37] considering the refractive index for particles as 1.435 [38-39]) which is very close to the optimal one. Such layers can be prepared by the LB method. Choosing a value for transmittance maximum in the middle wavelength range of visible light $(550 \mathrm{~nm}$ ) an optimal layer thickness of $110 \mathrm{~nm}$ (see Eq. 1., $\mathrm{n}=1.25$ ) was found.

For developing a refractive index gradient and broadening the wavelength range for enhanced transmittance another layer should be inserted between the substrate and the particulate layer. Compact silica sol-gel film is suitable for this purpose because of its refractive index ( $c a .1 .46$ [40] which is between the values for the substrate and the outer layer). Additionally it can 
provide an enhanced mechanical stability for the coating compared to single particulate LB

\subsubsection{Antireflective coatings for non-transparent substrates}

As non-transparent substrate silicon was chosen because of its importance in many practical applications (e.g. various semiconductor-based sensors, photodetectors, solar cells, semiconductor photonics, etc.). Considering its refractive index as 3.88 a layer with a refractive index of 1.97 is the most suitable for an antireflective coating (calculated from Eq. 2.). Therefore a titania sol-gel film with an effective refractive index value of 2.00 (as we determined in our recent work [33]) was chosen as the first layer. Choosing the wavelength corresponds to the minimal reflectance as $550 \mathrm{~nm}$ again, optimal thickness was found to be about $70 \mathrm{~nm}$ for this layer (see Eq. 1.).

A bilayered system was developed with a graded refractive index for non-transparent substrates, too. The second layer was decided to be a porous silica sol-gel film with a refractive index value between 1.3 and 1.4. Its thickness was determined using Eq. 1.

For the more precise calculation of layer thickness values simulated reflectance spectra of three different bilayered systems were compared. Layer thicknesses were chosen as 50, 65 and $80 \mathrm{~nm}$ for titania (refractive index: 2.00) and 76, 99 and $122 \mathrm{~nm}$ for porous silica (estimated refractive index: 1.31) sol-gel layers, respectively. Simulated spectra are displayed in Fig. 3. All combinations result in significantly decreased reflectance compared to the bare substrate. System with the thickest layers seem to be the less advantageous, both of other studied coatings provide antireflective property in the visible wavelength range (it depends on the chosen wavelength which is actually better).

Coating with a $65 \mathrm{~nm}$ thick titania and $99 \mathrm{~nm}$ porous silica sol-gel layers were chosen for our experiments. Reflectance spectra of such single films and their bilayers were simulated and displayed in Fig. 4. Results showed very similar tendencies compared to that for transparent substrates: single layer with near optimal refractive index (titania sol-gel film in this case) provided the lowest reflectance at a defined wavelength but the bilayer ensured decreased reflectance in a broader wavelength range.

Schematic structure of designed bilayers for non-transparent substrates is displayed in Fig. 2. b.

\subsection{Preparation of coatings}

For layer deposition processes microscope glass slides $(76 \times 26 \times 1 \mathrm{~mm}$, Thermo Scientific, Menzel-Gläser) and rectangular pieces of silicon wafers were used as solid substrates. They were washed with 2-propanol (a. r., $>99.7 \%$, Reanal) then rinsed with 2-propanol and distilled water $(18.2 \mathrm{M} \Omega \mathrm{cm}$, purified with a Millipore Simplicity 185 filtration system) and dried at room temperature before using. In case of single LB films substrates were additionally soaked 
in the mixture of sulphuric acid (ISO- For analysis, 98\%, Carlo Erba) and hydrogen peroxide (puriss, $30 \%$, Reanal) in a volume ratio of $2: 1$, rinsed again with distilled water and 2propanol and dried at room temperature. All of the layers were prepared at room temperature $(23 \pm 1){ }^{\circ} \mathrm{C}$.

\subsubsection{Preparation of sol-gel monolayers}

Two different types of silica precursor sols were prepared by the acid catalyzed, controlled hydrolysis of tetraethyl-orthosilicate (TEOS, for synthesis, $>99 \%$, Merck) in ethanol (a. r., $>99.7 \%$, Reanal). Hydrochloric acid ( $\mathrm{HCl}$, purum, 37\%, Fluka) was used as catalyst and it was added together with water as an aqueous $\mathrm{HCl}$ solution. Precursor sol (1) was synthesized for preparing compact silica sol-gel (cSiSG) films. The molar ratios for TEOS: ethanol: water: $\mathrm{HCl}$ were 1: 18.6: 5.5: $1 \times 10^{-3}$ and the mixture was stirred for $1 \mathrm{~h}$ at room temperature. Precursor sol (2) was suitable for depositing porous silica layers (pSiSG). In the synthesis process $2 \mathrm{~g}$ of Pluronic PE 10300 triblock copolymer (BASF, Ludwigshafen Germany) was dissolved in $22 \mathrm{~mL}$ of ethanol. Ethanol, TEOS and $0.1 \mathrm{M} \mathrm{HCl}$ were mixed in another beaker applying the same molar ratios as for the preparation of precursor sol (1) with the total volume of $35 \mathrm{~mL}$. Both mixtures were stirred for $30 \mathrm{~min}$ at room temperature and for additional $30 \mathrm{~min}$ after mixing the two solutions [41].

Titania precursor sol was prepared by acid-catalyzed hydrolysis of tetrabuthyl-orthotitanate in ethanol (TBOTi, purum, $>97 \%$, Fluka). TBOTi, absolute ethanol, deionized water and nitric acid $\left(\mathrm{HNO}_{3}, 65 \%\right.$, Carlo Erba) were mixed and stirred for two h at $60{ }^{\circ} \mathrm{C}$. Molar ratios were the following: TBOTi: ethanol: water: $\mathrm{HNO}_{3}=1: 27.4$ : 1.3: 0.3 [42].

Sol-gel films were prepared by the dip coating method: cleaned and dried glass or silicon substrate was immersed into the precursor sol and pulled out with a constant speed. A dip coater (MTA MFA, Hungary) was used for the process. Withdrawal speed values were varied between 1.6 and $19.3 \mathrm{~cm} / \mathrm{min}$ depending on the used precursor sol and the desired layer thickness. The deposited films were annealed in a drying oven (Nabertherm B170) at $450{ }^{\circ} \mathrm{C}$ for $30 \mathrm{~min}$ (or at $480{ }^{\circ} \mathrm{C}$ for $1 \mathrm{~h}$ for silica films prepared from precursor sol (2)) with a heating rate of $20^{\circ} \mathrm{C} / \mathrm{min}$ (and $5{ }^{\circ} \mathrm{C} / \mathrm{min}$ for titania films). In case of silica films type (2) Pluronic was decomposed and eliminated from the system at the temperature of annealing, resulted in a regular porous structure.

\subsubsection{Preparation of particulate $\mathrm{LB}$ films}

Silica nanoparticles with diameters of $84( \pm 9)$ and $131( \pm 10) \mathrm{nm}$ were prepared by the Stöber method [43] and used without any surface modification [44]. Size of the synthesized particles was controlled by changing the ratio of the used reagents. Size distribution functions of particles were determined from transmission electron microscopy images by measuring 300 particles for each system. Silica alcosols were diluted with chloroform (Ultra Resi-analyzed, $>99.8 \%$, J. T. Baker Inc.) in a volume ratio of 1:2 and homogenized in an ultrasonic bath (300 $\mathrm{W}$, Elma S15H) for $10 \mathrm{~min}$ (and for additional $2 \mathrm{~min}$ before each spreading).

Preparation of nanoparticulate LB films was carried out in a laboratory-built Wilhelmy film balance. A glass slide was immersed into the water and particles were spread onto the waterair interface using a $500 \mu \mathrm{l}$ micro syringe. Particulate film was compressed by a moving barrier with a constant speed of $8.1 \mathrm{~cm}^{2} / \mathrm{min}$ while the surface pressure was monitored by the Wilhelmy plate method. Particulate film was transferred onto the substrate by pulling out the slide with a speed of $1.2 \mathrm{~cm} / \mathrm{min}$ at $c a .80 \%$ of the respective collapse pressure of the film keeping its constant value. Films were dried in a drying oven at $110^{\circ} \mathrm{C}$ for $1 \mathrm{~h}$ with a heating rate of $3{ }^{\circ} \mathrm{C} / \mathrm{min}$. For determining the effect of heat treatment on the optical properties of LB films they were annealed at $450{ }^{\circ} \mathrm{C}$ for $30 \mathrm{~min}$ with a heating rate of $20^{\circ} \mathrm{C} / \mathrm{min}$. 


\subsubsection{Preparation of bilayered coatings}

Two basically different types of antireflective bilayers were prepared as it was described in sections 2.1.1-2. In the first case (cSiSG-LB) a compact silica sol-gel film (prepared from silica precursor sol (1)) was deposited with the appropriate withdrawal speed by dip coating on glass substrate and dried at room temperature for $\mathrm{ca}$. 10-15 $\mathrm{min}$. Then a nanoparticulate layer was prepared onto the sol-gel coating by the LB technique. The coating was finally annealed in a drying oven at $450{ }^{\circ} \mathrm{C}$ for $30 \mathrm{~min}$ (heating rate: $20^{\circ} \mathrm{C} / \mathrm{min}$ ). In the second case (TiSG-pSiSG) a titania layer was prepared by dip coating on silicon substrate and it was annealed at $450{ }^{\circ} \mathrm{C}$ for $30 \mathrm{~min}$ with a heating rate of $5{ }^{\circ} \mathrm{C} / \mathrm{min}$. Then a silica layer (from precursor sol (2), contained Pluronic) was deposited onto the surface of the titania film. Bilayer was annealed once again at $480{ }^{\circ} \mathrm{C}$ for $1 \mathrm{~h}$ (heating rate: $20^{\circ} \mathrm{C} / \mathrm{min}$ ). Main preparation steps for both bilayered systems are summarized in Table 1 . and their supposed schematic structure is displayed in Fig. 2.

\subsection{Optical characterization of coatings \\ 2.3.1 Optical measurements}

Optical properties of every monolayered coating (sol-gel or LB) and bilayers on glass substrates (cSiSG-LB) were investigated by UV-vis spectroscopy. Transmittance spectra of the films and bare substrates were taken using a Specord 200-0318 spectrophotometer in the wavelength range of 350-1100 nm with $1 \mathrm{~nm}$ resolution and a scanning speed of $5 \mathrm{~nm} / \mathrm{s}$.

From coatings on silicon substrates reflectance spectra were taken using a fiber coupled Avantes AvaSpec-2048 spectrometer with an Avantes HL-2000 halogen light source in the wavelength range of 330-1100 nm at near normal incidence. As reference, a silicon wafer was used. The reflectance spectrum of silicon was calculated using refractive index and extinction coefficient data for silicon given in the literature [31] and the relative reflectance values were multiplied by the theoretical reflectance of silicon.

\subsubsection{Evaluation of measured data}

For the final design of bilayered coatings study of optical properties of constituent single films was necessary. Investigation of monolayers was carried out on glass substrates in all cases. Layer thickness was tuned by controlling the particle size (for particulate LB films) or changing the withdrawal speed (for sol-gel films).

Measured spectra of single sol-gel, LB and bilayered coatings were evaluated by fitting them to calculated transmittance functions, obtained for appropriate models corresponding to the structure of the coating. The fitting procedures provided effective refractive index and film thickness values. As the glass substrate had weak absorption, the transmittance spectra were corrected before fitting to eliminate the absorption of their substrates [15, 32]. The fitting procedure used a Levenberg - Marquardt algorithm [45].

Transmittance spectra of sol-gel coatings were fitted with a homogeneous layer model [32] supposing identical homogeneous monolayers on both sides of the transparent substrate. Film thickness-withdrawal speed functions were determined for all used precursor sols based on the fitted thickness values using the Landau - Levich equation [46] (see Eq. 3., $d$ is the film thickness, $\mathrm{v}$ is the withdrawal speed, $\mathrm{g}$ is the gravitational acceleration, $\eta, \rho, \gamma_{\mathrm{LG}}$ are the dynamic viscosity, density and surface tension of the precursor sol, respectively). It could be done because all parameters in the equation (aside the layer thickness and the withdrawal speed) were considered to be constant for each sol at a defined time.

$$
\mathrm{d}=0.94 \frac{(\eta \mathrm{v})^{\frac{2}{3}}}{\gamma_{\mathrm{LG}}^{\frac{1}{6}}}(\rho g)^{\frac{1}{2}}
$$


In case of LB films three parallel samples were studied and their spectra were evaluated assuming a refractive index profile which corresponded to their supposed geometrical structure: a regular hexagonal array of monodisperse spherical particles [47].

Structure of bilayered coatings was designed using the model that supposes two optically homogeneous layers on each other. Thickness values for constituent single films were calculated using Eq. 1. (for details see section 2.1). Measured spectra of bilayers were evaluated using this model and fitted refractive index and layer thickness values were compared to the values used for simulations in case of both coating types.

\subsubsection{Effect of acidic treatment on the optical properties of coatings}

Effect of acidic treatment was studied on the optical properties of porous silica sol-gel films. Resistivity of coatings against acidic impacts can be very important from the aspect of potential outdoor practical applications since many environmental effects have acidic characteristics (e.g. rain, acid rain). Coatings were prepared for this purpose on glass substrates applying a withdrawal speed of $8 \mathrm{~cm} / \mathrm{min}$ and were immersed into hydrochloric acid with $\mathrm{pH}$ value of 0 or 3 and were held there for $3 \mathrm{~h}$ under vigorous stirring. Slides were dried afterwards at room temperature for $24 \mathrm{~h}$. Transmittance spectra for films were taken before and after treatment.

\subsection{Structural characterization of bilayered coatings}

In-depth structure of antireflective bilayers was studied by Field Emission Scanning Electron Microscopy (FFESEM). For this purpose both types of bilayered coatings (cSiSG-LB and TiSG-pSiSG) were prepared onto silicon substrates. Cross-section FESEM images were taken using a LEO $1540 \mathrm{XB}$ field emission scanning electron microscope.

\section{Results and Discussion}

Transmittance spectra were taken from single LB, various types of sol-gel and bilayered coatings and evaluated using different theoretical models. The reduced chi-square values of the fitting were in the range of $10^{-7}$ and the coefficient of determination $\left(\mathrm{R}^{2}\right)$ value was usually above 0.999 which indicated a very good agreement between measured and calculated spectra.

Bilayered coatings for both types were designed based on the fitted refractive index and layer thickness results obtained for single LB and sol-gel films.

\subsection{Antireflective coatings on transparent substrates \\ 3.1.1 Optical properties of the single particulate LB films}

Transmittance spectra of annealed particulate LB monolayers on glass substrates showed enhanced transmittance as expected for the whole studied wavelength range (see Fig. 5.). Spectra had a maximum above 0.994 and the corresponding wavelength increased with particle size. For the evaluation of the spectra of LB films the model was applied which supposed a monolayer of close-packed spheres. The results of fitting were collected in Table 2.

The fitted refractive index values were 1.228 and 1.245 which confirmed the colloidal, nearly close-packed structure of the nanoparticulate LB films. The layer thickness values were about $10 \%$ smaller compared to the TEM diameter of particles for both studied particle sizes. This experience and the slight decrease of the refractive index compared to the calculated value of 1.25 (see section 2.1.1) could be attributed to the potential shrinkage of the particles during the heat treatment. Thickness of annealed layers was very close to the calculated optimal values (80 and $110 \mathrm{~nm}$, see section 2.1.1) for antireflective coatings at wavelength ranges 
around 400 and $550 \mathrm{~nm}$, respectively. Low values for standard deviations showed that optical properties of LB films had a good reproducibility.

\subsubsection{Optical properties of the single compact silica sol-gel films}

Prepared compact silica sol-gel coatings had higher transmittance than that of their bare substrates for the whole studied wavelength range for every withdrawal speed (see Fig. 6.). Their spectra had a maximum at transmittance value of $c a$. 0.94-0.95 and the corresponding wavelength increased with the withdrawal speed. Transmittance spectra were fitted with the homogeneous layer model and the resulting refractive index and film thickness values are in Table 3.

The refractive index values were mostly between 1.45 and 1.46 reinforcing the supposed compact structure of the coatings. Film thickness values were in the range of $60-120 \mathrm{~nm}$ which means precursor sol was suitable for the preparation of the appropriate layer in the bilayered antireflective coatings (see section 2.1.1).

Thickness was found to be directly proportional to the $2 / 3^{\text {rd }}$ power of withdrawal speed satisfying the Landau - Levich equation in the studied range so the correlation between thickness and withdrawal speed could be determined (see Fig. 7.). Refractive index values were found to be independent from the withdrawal speed in the studied range.

\subsubsection{Final design and optical characterization of bilayered coatings}

For detailed designing the structure of bilayered cSiSG-LB type coatings on glass substrate wavelengths for transmittance maximum $\left(\lambda_{\max }\right)$ for annealed LB films were calculated substituting the fitted refractive index and layer thickness values (Table 2.) into Eq. 1. Originally targeted wavelengths (400 and $550 \mathrm{~nm}$, see section 2.1 .1 ) were adjusted this way to the real size of the synthesized particles. Thickness of the corresponding compact silica solgel film (with the same $\lambda_{\max }$ ) was also calculated with Eq. 1. assuming the refractive index as 1.46 (see Table 3.). Based on the resulting thickness values the withdrawal speed was calculated using the previously determined layer thickness-withdrawal speed function. Results of calculations were collected in Table 4. Combined coatings were prepared applying the determined parameters.

Measured spectra of bilayered coatings showed that they had an enhanced transmittance in the whole studied wavelength range compared to their bare substrates (see Fig. 8.). Both transmittance spectra showed maximum values above 0.992 .

Measured and simulated spectra of combined coatings had similar shape and the wavelengths corresponding to the maximum transmittance values were approximately the same (see Fig. 1. and 8.). Measured spectra were fitted to the calculated ones applying the model used for previous simulations (assuming the coating as two homogeneous layers). Targeted and fitted refractive index and layer thickness values (collected in Table 5.) showed very good agreement in case of coatings contained $84 \mathrm{~nm}$ particles. For bigger $(131 \mathrm{~nm})$ particles agreement remained reasonable but slight differences occurred (probably due to the increasing inhomogeneity and light scattering effect of particles).

Comparing the spectra to that of single LB films it was found that interference peaks became less sharp resulting in a slightly broader wavelength range of enhanced transmittance as it was expected based on the simulations. Results also showed that this range could be consciously varied by changing the particle size.

\subsection{Antireflective coatings on non-transparent substrates 3.2.1 Optical properties of single sol-gel films}

As it was described in section 2.1.2 titania and porous silica sol-gel films were chosen as the constituent layers for the antireflective bilayer on silicon substrate. 
Transmittance spectra of titania sol-gel films prepared on glass substrates had a minimum of $0.60-0.65$ (see Fig. 9.). Fitted results showed that they have the highest refractive index (1.962.01) among the investigated samples with a film thickness of 50-85 $\mathrm{nm}$ (see Table 6.).

Porous silica sol-gel coatings had higher transmittance than that of their bare glass substrates for the whole studied wavelength range for every withdrawal speed (see Fig. 10.). Spectra had maxima higher than 0.99 above the withdrawal speed of $4.8 \mathrm{~cm} / \mathrm{min}$. Refractive index values were much lower compared to that for compact silica films in most cases (1.31-1.38) as expected and the thickness values were between 75 and $160 \mathrm{~nm}$. Refractive index values were fluctuated, but in the middle range of withdrawal speeds found to be approximately constant (ca. 1.31).

Thickness was found to be directly proportional to the $2 / 3^{\text {rd }}$ power of withdrawal speed in the studied range in both cases so the correlation between thickness and withdrawal speed could be determined for these precursor sols, too (see Fig. 7. and Table 6.).

\subsubsection{Final design and optical characterization of bilayered coatings}

Since estimated effective refractive index for titania and porous silica sol-gel films (2.00 and 1.31 , respectively) could be reasonably reproduced experimentally, only layer thicknesses had to be adjusted. For previously calculated thickness values $(65 \mathrm{~nm}$ for titania and $99 \mathrm{~nm}$ for silica layer, see section 2.1.2) corresponding withdrawal speeds were determined (see Fig. 7. and Table 6.) and found to be $12.6 \mathrm{~cm} / \mathrm{min}$ for titania and $3.6 \mathrm{~cm} / \mathrm{min}$ for silica films. Coating was prepared on silicon substrate applying these values. Reflectance spectra of native silicon substrate, titania layer and TiSG-pSiSG bilayer (measured and fitted) are displayed in Fig. 11. Measured reflectance curve for the bilayer was fitted to the calculated one applying the model used for previous simulations (fitted results are in Table 7.).

Bilayered coating owns a reflectance value below about $10 \%$ of the reflectance for bare silicon substrate for the whole studied wavelength range (but it is lower in some ranges: e.g. below $5 \%$ between 650 and $750 \mathrm{~nm}$ ). Above $c a .570 \mathrm{~nm}$ bilayered system has a significantly decreased reflectance compared to the single titania layer. Though single titania sol-gel film showed the lowest reflectance at $c a$. $500 \mathrm{~nm}$, wavelength range for decreased reflectance could be significantly broadened applying the prepared TiSG-cSiSG bilayer.

Measured and simulated TiSG-pSiSG curves showed very similar shape and fitted refractive index and layer thickness values showed good agreement with the values used for simulations. It means that the simulation supposing two optically homogeneous layers can provide a reasonable approximation for predicting the optical properties of such bilayered coatings.

Antireflective property of TiSG-pSiSG coatings could be visually observed since coating owned a dark (almost black) color showing a sharp contrast compared to strongly reflective bare silicon substrate (see Fig. 12.).

\subsubsection{Chemical stability of sol-gel coatings}

Chemical stability of porous silica sol-gel films (the outer layer of the prepared TiSG-pSiSG antireflective coating) was studied by treating them in strongly acidic media (at $\mathrm{pH}$ values of 0 and 3). Difference of transmittance caused by the treatment is displayed in Fig. 13.

Results show that acidic treatment did not change significantly the optical properties. Difference between transmittance values measured before and after treatment stayed below 0.002 for the whole studied wavelength range indicating a chemically stable structure under these circumstances. It makes such coatings more suitable for practical applications since they showed enhanced resistance against potentially acidic type environmental effects. 


\subsection{In-depth structure of antireflective bilayers}

\section{Design, preparation and optical characterization of two different types of antireflective}

bilayers were carried out in this work by simple and low-cost colloid chemical methods. Layer structures were determined in order to get the most advantageous refractive index profile. Structure of coatings was designed by simulations approximating the coatings as the combination of two optically homogeneous (effective) layers. Preparations were carried out by applying the calculated parameters and coatings were finally studied by UV-vis spectroscopy and FESEM.

In case of transparent, glass substrates compact silica sol-gel film and a close-packed layer of Stöber silica nanoparticles were applied providing transmittance above 0.975 in the $450 \mathrm{~nm}$ $1000 \mathrm{~nm}$ wavelength range.

In case of non-transparent, silicon substrates the bilayered coatings were composed of a titania and a porous silica sol-gel layer. The prepared bilayered structure showed a reflectance below $4 \%$ above $450 \mathrm{~nm}$ which is significantly lower compared to the value for the bare substrate $(>30 \%)$. Chemical stability of the outer porous silica sol-gel layer was proven by its unchanged optical characteristics after long time treatment in strongly acidic environment. It was shown that by choosing the appropriate layer structures various bilayered antireflective coatings can be designed and prepared on transparent or non-transparent substrates using wet colloid chemical methods like dip coating and Langmuir - Blodgett technique. Applying porous silica sol-gel film as the outer layer can improve the suitability of the coatings for practical applications due to its resistivity against acidic type effects.

\section{Acknowledgements}

The authors thank Erzsébet Hild for her help in optical issues, Attila L. Kovács for the TEM and András Deák for the FESEM images. The financial support of the Hungarian Scientific Research Fund (OTKA CK 78629), NKTH - A*STAR Hungarian - Singaporean Bilateral S\&T International Co-operation (BIOSPONA) and the New Széchenyi Plan (TÁMOP4.2.1/B-09/1/KMR-2010-0002) is gratefully acknowledged.

\section{References}

[1] C. J. Brinker, G. W. Scherer, Sol-Gel Science - The Physics and Chemistry of Sol-Gel Processing, Academic Press, San Diego, 1990.

[2] C. T. Kresge, M. E. Leonowicz, W. J. Roth, J. C. Vartuli, J. S. Beck, Nature 359 (1992) $710-712$.

[3] D. Zhao, J. Feng, Q. Huo, N. Melosh, G. H. Fredrickson, B. F. Chmelka, G. D. Stucky, Science 279 (1998) 548-552. 
[4] R. Ryoo, C. H. Ko, S. J. Cho, J. M. Kim, J. Phys. Chem. B 101 (1997) 10610-10613.

[5] G. J. de A. A. Soler-Illia, E. L. Crepaldi, D. Grosso, C. Sanchez, Curr. Op. Colloid Interface Sci. 8 (2003) 109-126.

[6] N. Carr, M. J. Goodwin, K. J. Harrison, K. L. Lewis, Thin Solid Films 230 (1993) 59-64.

[7] A. Vasicek, Optics of Thin Films, North-Holland Publishing Company, Amsterdam, 1960.

[8] M. V. Klein, T. E. Furtak, Optics, second ed., John Wiley \& Sons, New York, 1986.

[9] H. A. Macleod, Thin Film Optical Filters, second ed., Adam Hilger Ltd., Bristol, UK, 1986.

[10] J. Moghal, J. Kobler, J. Sauer, J. Best, M. Gardener, A. A. R. Watt, G. Wakefield, Appl. Mater. Interfaces 4 (2012) 854-859.

[11] S. Kim, J. Cho, K. Char, Langmuir, 23 (2007) 6737-6743.

[12] A.-L. Pénard, T. Gacoin, J.-P. Boilot, Acc. Chem. Res. 40 (2007) 895-902.

[13] G. Wu, J. Wang, J. Shen, T. Yang, Q. Zhang, B. Zhou, Z. Deng, B. Fan, D. Zhou, F. Zhang, Mat. Sci. Eng. B 78 (2000) 135-139.

[14] S. Strehlke, S. Bastide, J. Guillet, C. Lévy-Clément, Mat. Sci. Eng. B 69-70 (2000) 8186.

[15] D. S. Hinczewski, M. Hinczewski, F. Z. Tepehan, G. G. Tepehan, Sol. Energy Mater. Sol. Cells 87 (2005) 181-196.

[16] R. B. Pettit, C. J. Brinker, C. S. Ashley, Sol. Cells 15 (1985) 267-278.

[17] B. S. Richards, Sol. Energy Mater. Sol. Cells 79 (2003) 369-390.

[18] L. Naszályi, N. Ábrahám, E. Hild, D. Cot, A. Ayral, Z. Hórvölgyi, Langmuir 24 (2008) 12575-12580.

[19] M. Manca, A. Cannavale, L. De Marco, A. S. Arico, R. Cingolani, G. Gigli, Langmuir 25 (2009) 6357-6362.

[20] S. J. Collins, A. Dhathathreyan, T. Ramasami, H. Möhwald, Thin Solid Films 358 (2000) 229-233.

[21] S. Reculusa, P. Masse, S. Ravaine, J. Coll. Interface Sci. 279 (2004) 471-478.

[22] S. Reculusa, S. Ravaine, Appl. Surf. Sci. 246 (2005) 409-414.

[23] L. Naszályi, A. Deák, E. Hild, A. Ayral, A.L. Kovács, Z. Hórvölgyi, Thin Solid Films 515 (2006) 2587-2595. 
[24] S. Reculusa, R. Perrier-Cornet, B. Agricole, V. Heroguez, T. Buffeteau, S. Ravaine, Phys. Chem. Chem. Phys. 9 (2007) 6385-6390.

[25] J. H. Kim, H. S. Kim, J. H. Lee, S. W. Choi, Y. J. Cho, J. H. J. Kim, Nanoscience Nanotechnology 9 (2009) 7007-7011.

[26] M. Bardosova, M. E. Pemble, I. M. Povey, R. H. Tredgold, Adv. Mater. 22 (2010) 31043124.

[27] N. Ábrahám, D. Sebők, S. Papp, L. Körösi, I. Dékány, Colloids Surf. A: Physicochem. Eng. Asp. 384 (2011) 80-89.

[28] B. G. Prevo, Y. Hwang, O. D. Velev, Chem. Mater. 17 (2005) 3642-3651.

[29] W. Zhou, M. Tao, L. Chen, H. Yang, J. Appl. Phys. 102 (2007) 103105.

[30] P. Spinelli, M. A. Verschuuren, A. Polman, Nat. Commun. 3 (2012) 692.

[31] D. E. Aspnes, J. B. Theeten, J. Electrochem. Soc. 127 (1980) 1359-1365.

[32] E. Hild, A. Deák, L. Naszályi, Ö. Sepsi, N. Ábrahám, Z. Hórvölgyi, J. Opt. A: Pure Appl. Opt. 9 (2007) 920-930.

[33] Á. Detrich, E. Hild, N. Nagy, E. Volentiru, Z. Hórvölgyi, Thin Solid Films 2012, 520 (2012) 2537-2544.

[34] H. A. Lorentz, Theory of Electrons, second ed., Teubner, Leipzig, Germany, 1916.

[35] E. S. Kooij, H. Wormeester, E. A. M. Brouwer, E. van Vroonhoven, A. van Silfhout, B. Poelsema, Langmuir 18 (2002) 4401-4413.

[36] D. Grigoriev, D. Gorin, G. Sukhorukov, A. Yashchenok, E. Maltseva, H. Möhwald, Langmuir 23 (2007) 12388-12396.

[37] N. Nagy, A. Deák, Z. Hórvölgyi, M. Fried, A. Agod, I. Bársony, Langmuir 22 (2006) 8416-8423.

[38] F. García-Santamaría, H. Míguez, M. Ibisate, F. Meseguer, C. López, Langmuir 18 (2002) 1942-1944.

[39] M. Szekeres, O. Kamalin, P.G. Grobet, R.A. Schoonheydt, K. Wostyn, K. Clays, A. Persoons, I. Dékány, Colloid Surf. A 227 (2003) 77-83.

[40] I. H. Malitson, J. Opt. Soc. Am. 55 (1965) 1205-1209.

[41] T. S. Vaishnavi, P. Haridoss, C. Vijayan, Mat. Lett. 62 (2008) 1649-1651.

[42] C. Trapalis, N. Todorova, M. Anastasescu, C. Anastasescu, M. Stoica, M. Gartner, M. Zaharescu, T. Stoica, Thin Solid Films 517 (2009) 6243-6247.

[43] W. Stöber, A. Fink, E. Bohn, J. Colloid Interface Sci. 26 (1968) 62-69. 
[44] M. Bardosova, F. C. Dillon, M. E. Pemble, I. M. Povey, R. H. Tredgold, J. Colloid Interface Sci. 333 (2009) 816-819.

[45] W. H. Press, B. P. Flannery, S. A. Teukolsky, W. T. Vetterling, Numerical Recipes in C, The Art of Scientific Computing, Cambridge University Press, New York, 1988.

[46] L. Landau, B. Levich, Acta Physicochim. URSS. 17 (1942) 42-54.

[47] E. Hild, T. Seszták, D. Völgyes, Z. Hórvölgyi, Prog. Colloid Polym. Sci. 125 (2004) 6167. 


\begin{tabular}{ccc} 
Steps & $\begin{array}{c}\text { cSiSG-LB, Type 1 } \\
\text { (substrate: glass) }\end{array}$ & $\begin{array}{c}\text { TiSG-pSiSG, Type 2 } \\
\text { (substrate: silicon) }\end{array}$ \\
\hline 1 & Dip: compact $\mathrm{SiO}_{2} \mathrm{SG}(1)$ & Dip: $\mathrm{TiO}_{2} \mathrm{SG}$ \\
2 & Drying on $\mathrm{RT}$ & $\mathrm{TA}: 450{ }^{\circ} \mathrm{C}, 30 \mathrm{~min}$ \\
3 & $\mathrm{LB}: \mathrm{SiO}_{2}$ & Dip: porous $\mathrm{SiO}_{2} \mathrm{SG}(2)$ \\
4 & $\mathrm{TA}: 450^{\circ} \mathrm{C}, 30 \mathrm{~min}$ & $\mathrm{TA}: 480^{\circ} \mathrm{C}, 1 \mathrm{~h}$
\end{tabular}


Table 2

\begin{tabular}{ccc}
\multirow{2}{*}{ Sample } & \multicolumn{2}{c}{ Results of fitting } \\
& $\begin{array}{c}\text { Effective } \\
\text { refractive index }\end{array}$ & $\begin{array}{c}\text { Layer thickness } \\
{[\mathrm{nm}]}\end{array}$ \\
\hline \multirow{2}{*}{$84 \mathrm{~nm} \mathrm{LB}$} & 1.245 & 79 \\
& $( \pm 0.010)$ & $( \pm 0.6)$ \\
$131 \mathrm{~nm} \mathrm{LB}$ & 1.228 & 115 \\
& $( \pm 0.006)$ & $( \pm 1.2)$
\end{tabular}


Table 3

\begin{tabular}{cccc} 
Sol-gel film & $\begin{array}{c}\text { Withdrawal speed } \\
\text { [cm/min] }\end{array}$ & \multicolumn{2}{c}{ Results of fitting } \\
Refractive index & $\begin{array}{c}\text { Layer thickness } \\
\text { [nm] }\end{array}$ \\
\hline \multirow{2}{*}{ cSiSG } & 3 & 1.476 & 63 \\
& 7.5 & 1.458 & 92 \\
& 12 & 1.459 & 119
\end{tabular}


Table 4

\begin{tabular}{cccc} 
Sample & $\begin{array}{c}\text { Calculated } \\
\text { wavelength for } \\
\text { transmittance } \\
\text { maximum } \\
\text { [nm] }\end{array}$ & $\begin{array}{c}\text { Appropriate } \\
\text { thickness for } \\
\text { sol-gel films } \\
\text { [nm] }\end{array}$ & $\begin{array}{c}\text { Appropriate } \\
\text { withdrawal } \\
\text { speed } \\
\text { [cm/min] }\end{array}$ \\
\hline $84 \mathrm{~nm} \mathrm{LB}$ & 393 & 68 & 3.7 \\
$131 \mathrm{~nm} \mathrm{LB}$ & 565 & 97 & 8.1
\end{tabular}




\begin{tabular}{|c|c|c|c|c|c|c|c|c|}
\hline \multirow{3}{*}{ Sample } & \multicolumn{4}{|c|}{ 1. layer (cSiSG) } & \multicolumn{4}{|c|}{ 2. layer $(\mathrm{LB})$} \\
\hline & \multicolumn{2}{|c|}{$\begin{array}{c}\text { Effective } \\
\text { refractive index }\end{array}$} & \multicolumn{2}{|c|}{$\begin{array}{c}\text { Layer thickness } \\
{[\mathrm{nm}]}\end{array}$} & \multicolumn{2}{|c|}{$\begin{array}{l}\text { Effective } \\
\text { refractive index }\end{array}$} & \multicolumn{2}{|c|}{$\begin{array}{c}\text { Layer thickness } \\
\text { [nm] }\end{array}$} \\
\hline & target & fitted & target & fitted & target & fitted & target & fitted \\
\hline $\begin{array}{c}c S i S G \\
+\end{array}$ & 1.460 & 1.459 & 68 & 65 & 1.245 & 1.237 & 79 & 79 \\
\hline $\begin{array}{l}84 \text { nm LB } \\
\quad c S i S G\end{array}$ & & & & & & & & \\
\hline$\stackrel{+}{+}$ & 1.460 & 1.477 & 97 & 94 & 1.228 & 1.280 & 115 & 124 \\
\hline
\end{tabular}




\begin{tabular}{cccc} 
Sol-gel film & $\begin{array}{c}\text { Withdrawal speed } \\
\text { [cm/min] }\end{array}$ & $\begin{array}{c}\text { Results of fitting } \\
\text { Refractive index }\end{array}$ & $\begin{array}{c}\text { Layer thickness } \\
\text { [nm] }\end{array}$ \\
\hline \multirow{3}{*}{ TiSG } & 9.7 & 2.009 & 53 \\
& 12.1 & 1.982 & 60 \\
& 14.5 & 2.000 & 74 \\
16.9 & 2.001 & 82 \\
& 19.3 & 1.955 & 83 \\
\hline \multirow{2}{*}{ pSiSG } & 1.6 & 1.430 & 75 \\
& 3.2 & 1.380 & 93 \\
& 4.8 & 1.308 & 110 \\
& 6.4 & 1.312 & 133 \\
\end{tabular}




\begin{tabular}{ccccccccc} 
& \multicolumn{3}{c}{ 1. layer (TiSG) } & \multicolumn{2}{c}{ 2. layer (pSiSG) } \\
Sample & \multicolumn{2}{c}{$\begin{array}{c}\text { Effective } \\
\text { refractive index }\end{array}$} & \multicolumn{2}{c}{ Layer thickness } & \multicolumn{2}{c}{$\begin{array}{c}\text { Effective } \\
\text { [nm] }\end{array}$} & $\begin{array}{c}\text { refractive index } \\
\text { refayer thickness }\end{array}$ & \multicolumn{2}{c}{ [nm] } \\
& target & fitted & target & fitted & target & fitted & target & fitted \\
\hline TiSG-pSiSG & 2.000 & 1.994 & 65 & 66 & 1.310 & 1.312 & 99 & 95
\end{tabular}




\section{List of Table Captions}

Table 1.: Summary of the preparation steps of studied bilayered coatings (SG means sol-gel film, RT and TA stand for room temperature and temperature of annealing, respectively)

Table 2. Fitted effective refractive index and film thickness values determined from transmittance spectra for nanoparticulate silica LB films after annealing (displayed results are the average of three parallel values, standard deviations are in brackets)

Table 3. Fitted refractive index and film thickness values determined from transmittance spectra for compact silica sol-gel films prepared with different withdrawal speeds

Table 4. Calculated thickness of sol-gel films and the corresponding withdrawal speed values for the preparation of the appropriate combined coatings

Table 5. Fitted refractive index and film thickness values determined from transmittance spectra for cSiSG-LB type bilayers; values used for simulations (target) are also displayed

Table 6. Fitted refractive index and film thickness values determined from transmittance spectra for porous silica and titania sol-gel films prepared with different withdrawal speeds

Table 7. Fitted refractive index and film thickness values determined from reflectance spectra for TiSG-pSiSG type bilayers; values used for simulations (target) are also displayed 


\section{Transmittance}

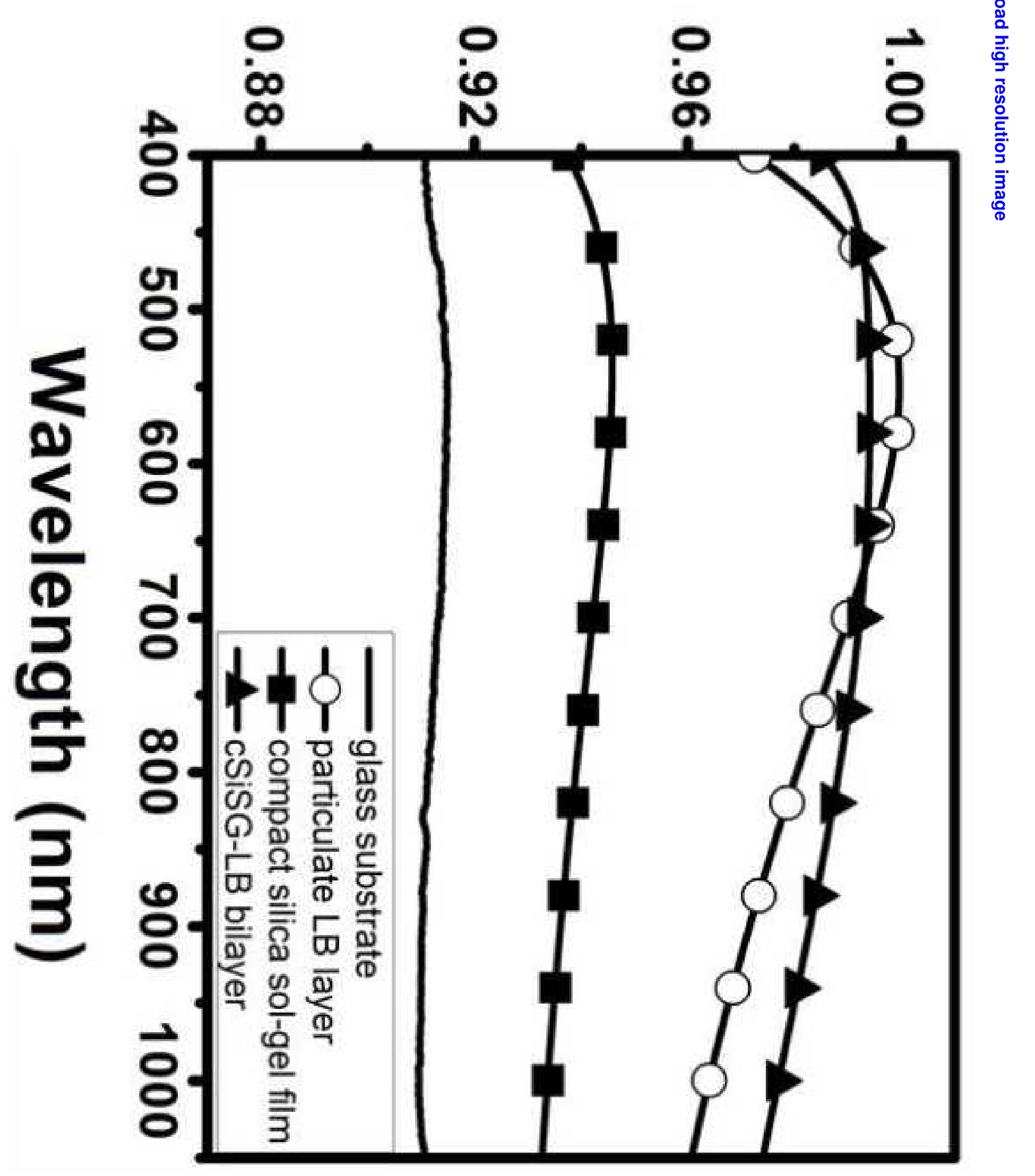




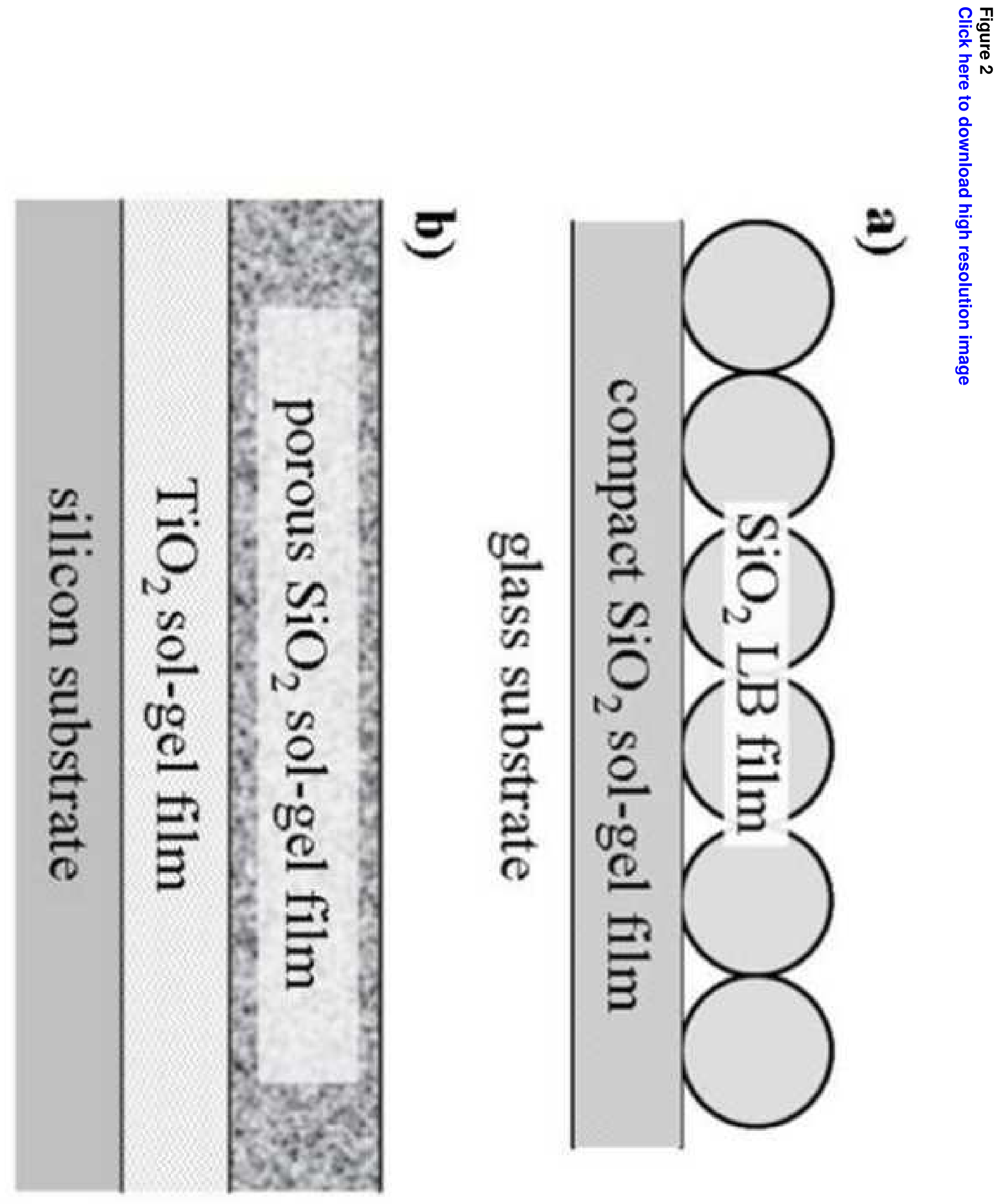




\section{Reflectance}

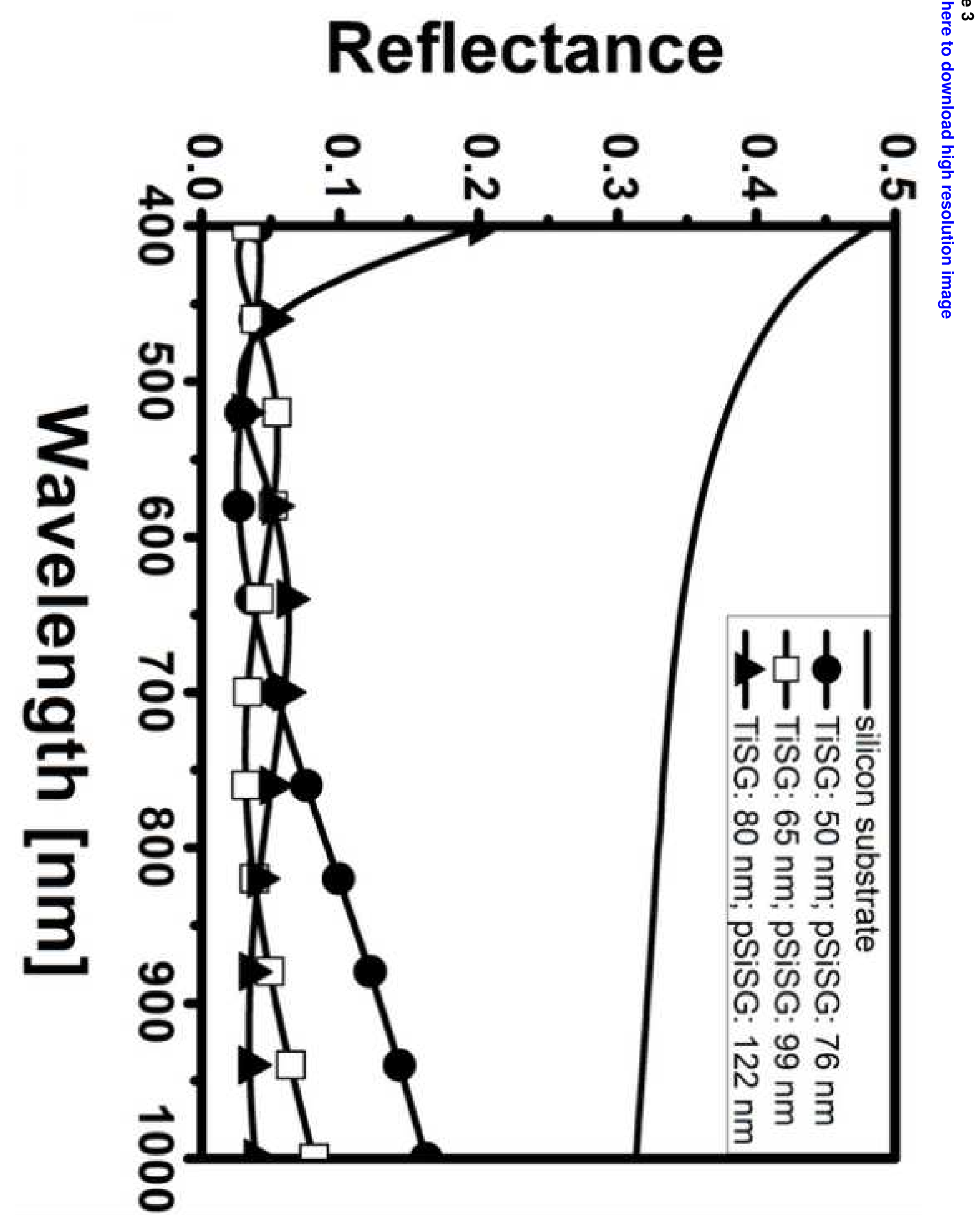




\section{Reflectance}

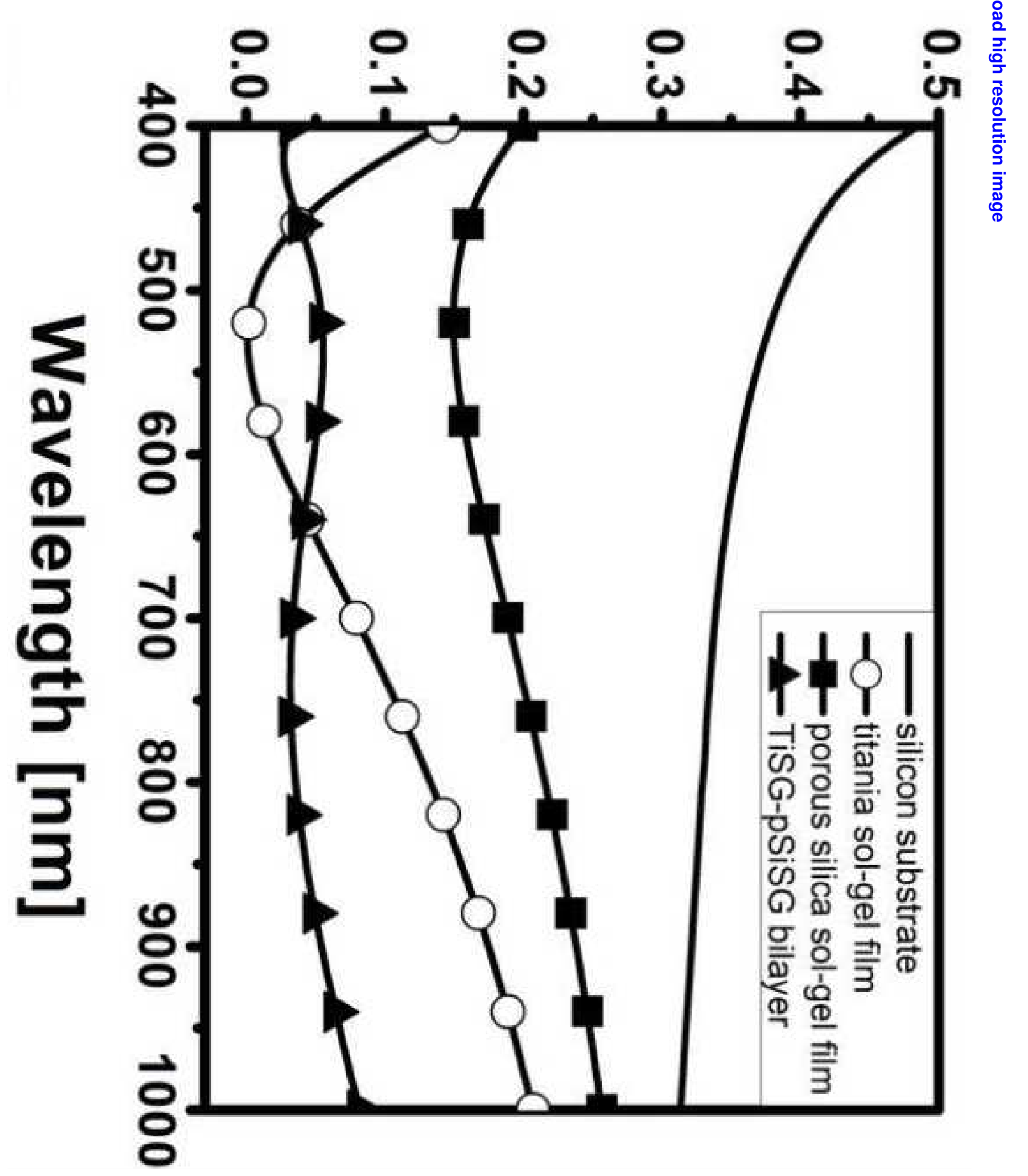




\section{Transmittance}

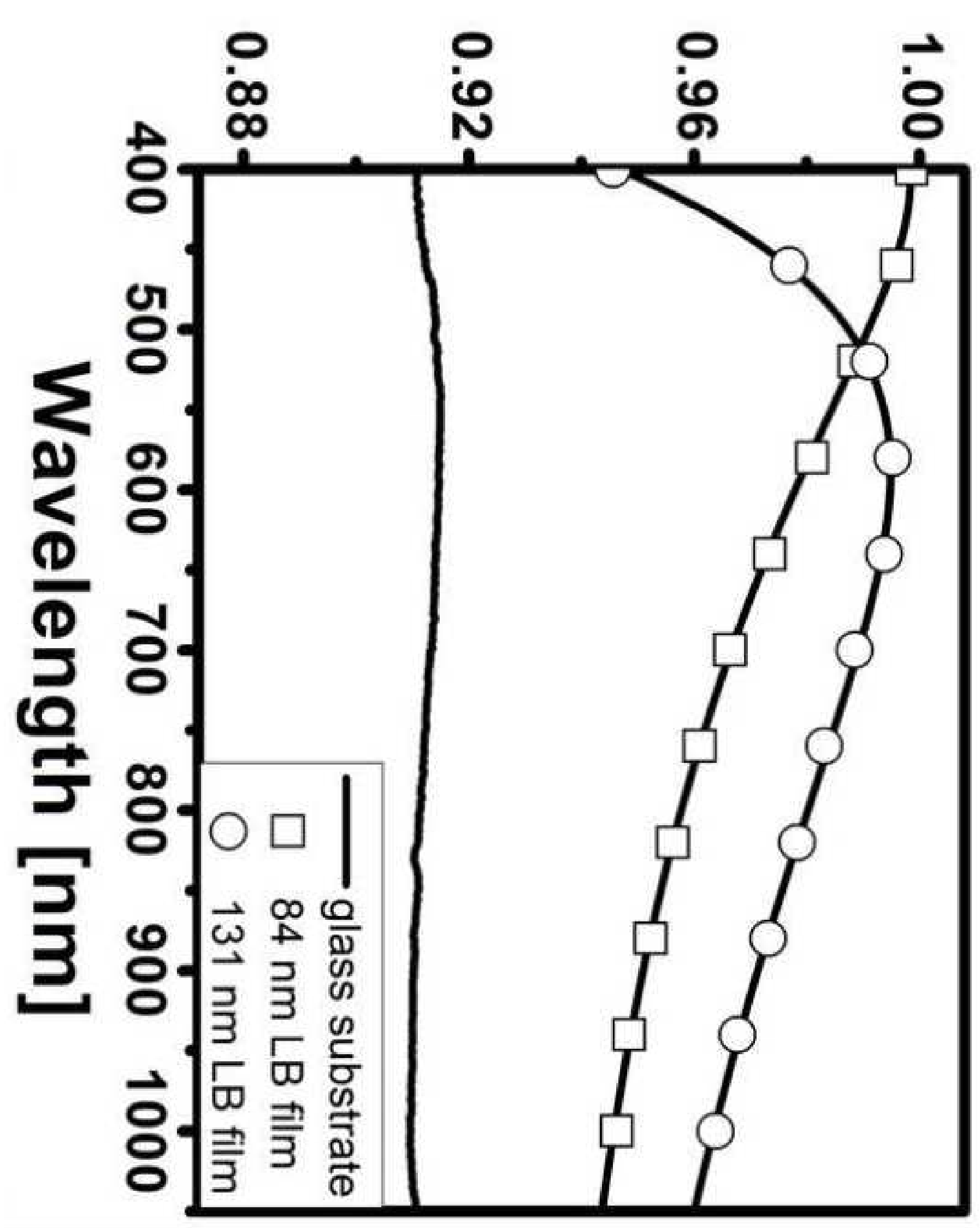

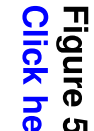




\section{Transmittance}

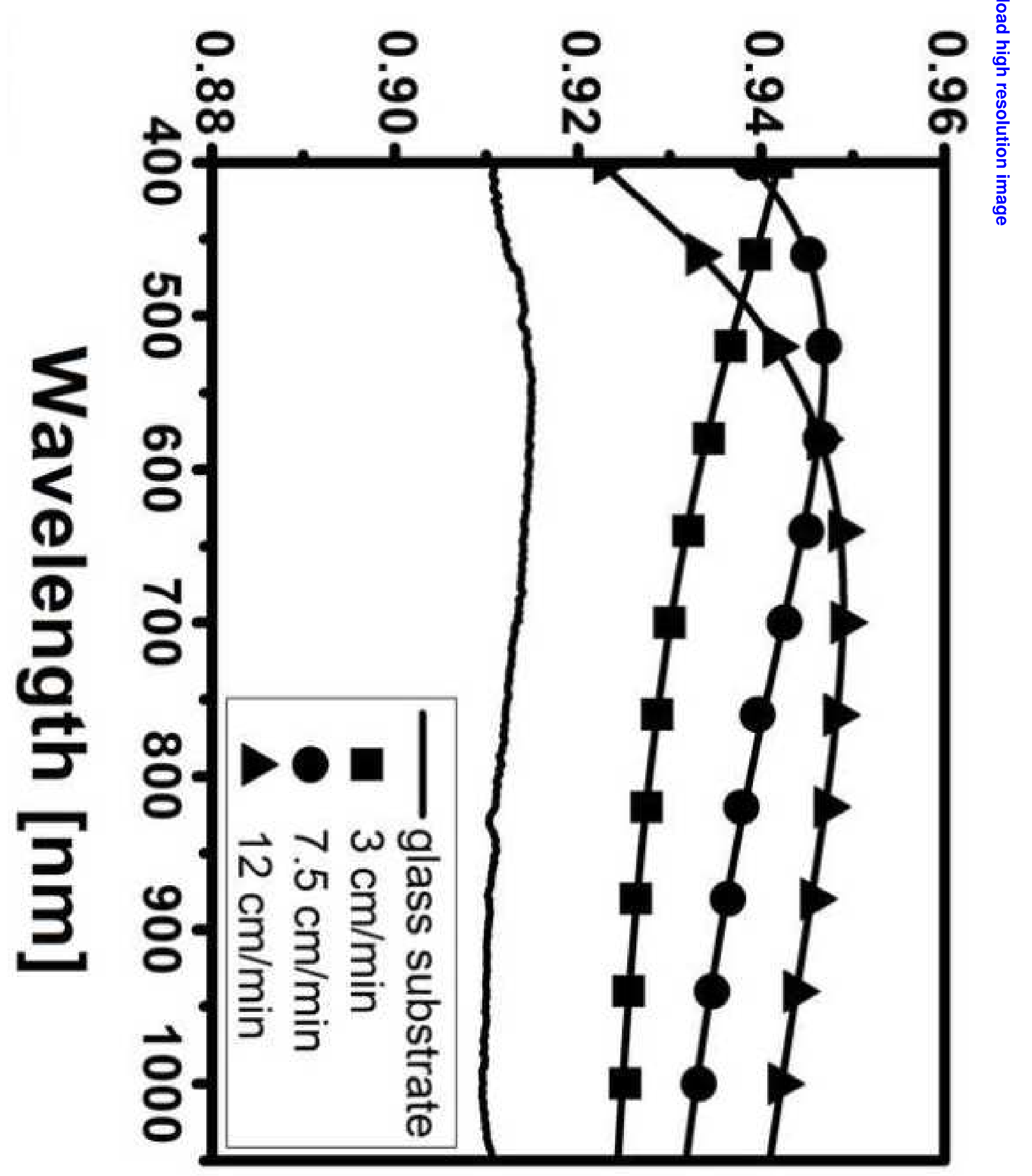




\section{Layer thickness [nm]}

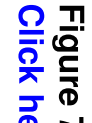

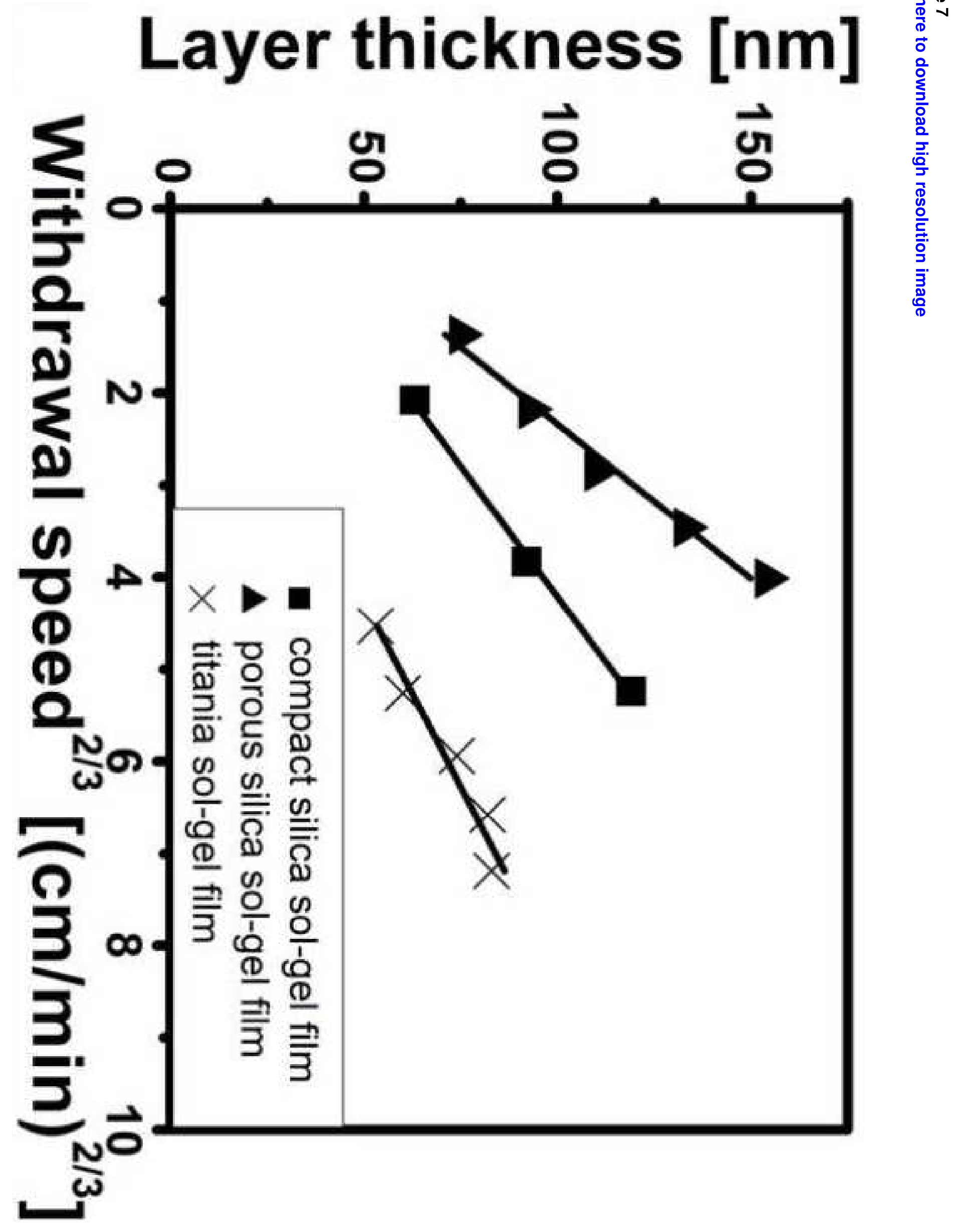




\section{Transmittance}

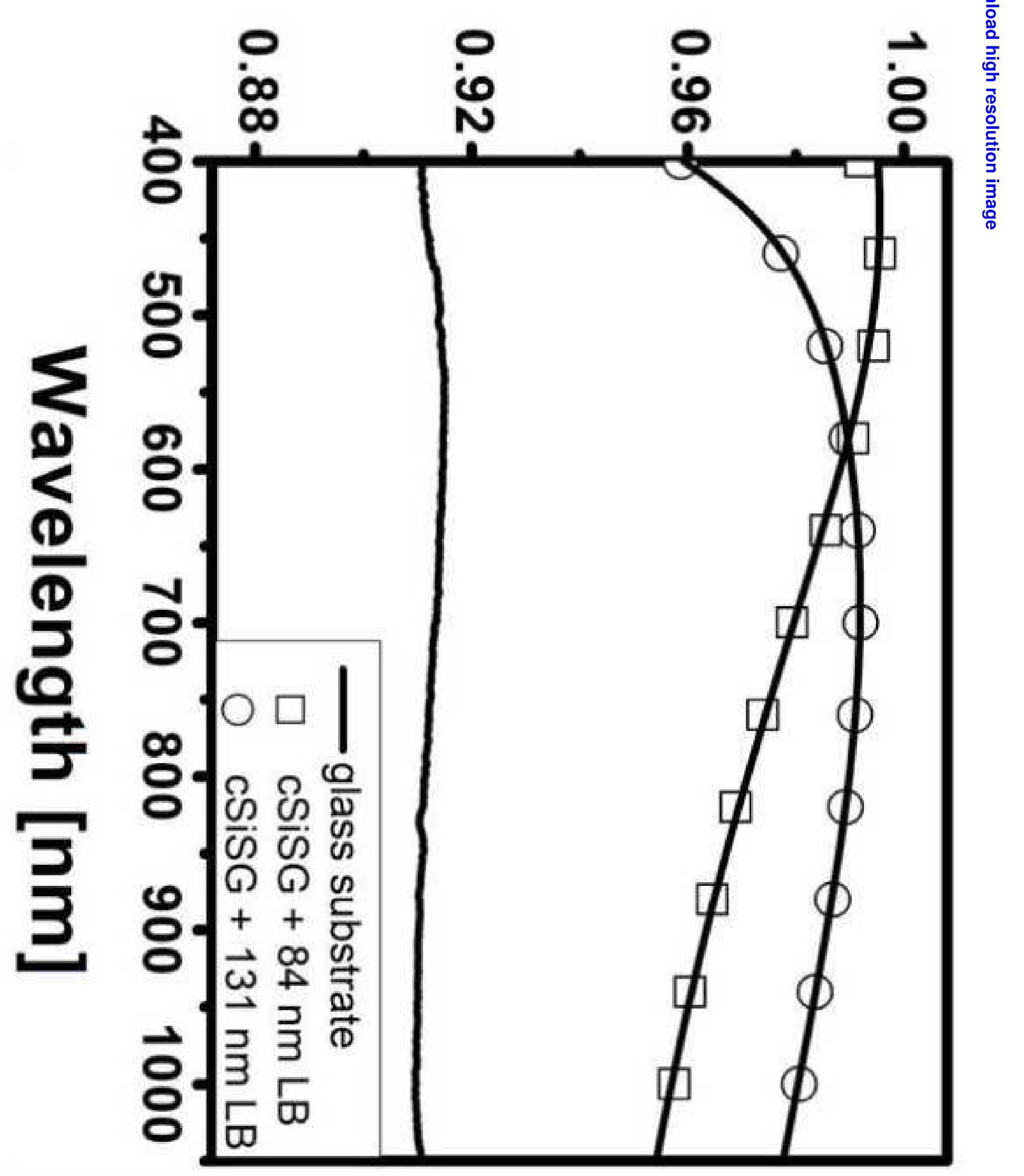




\section{Transmittance}

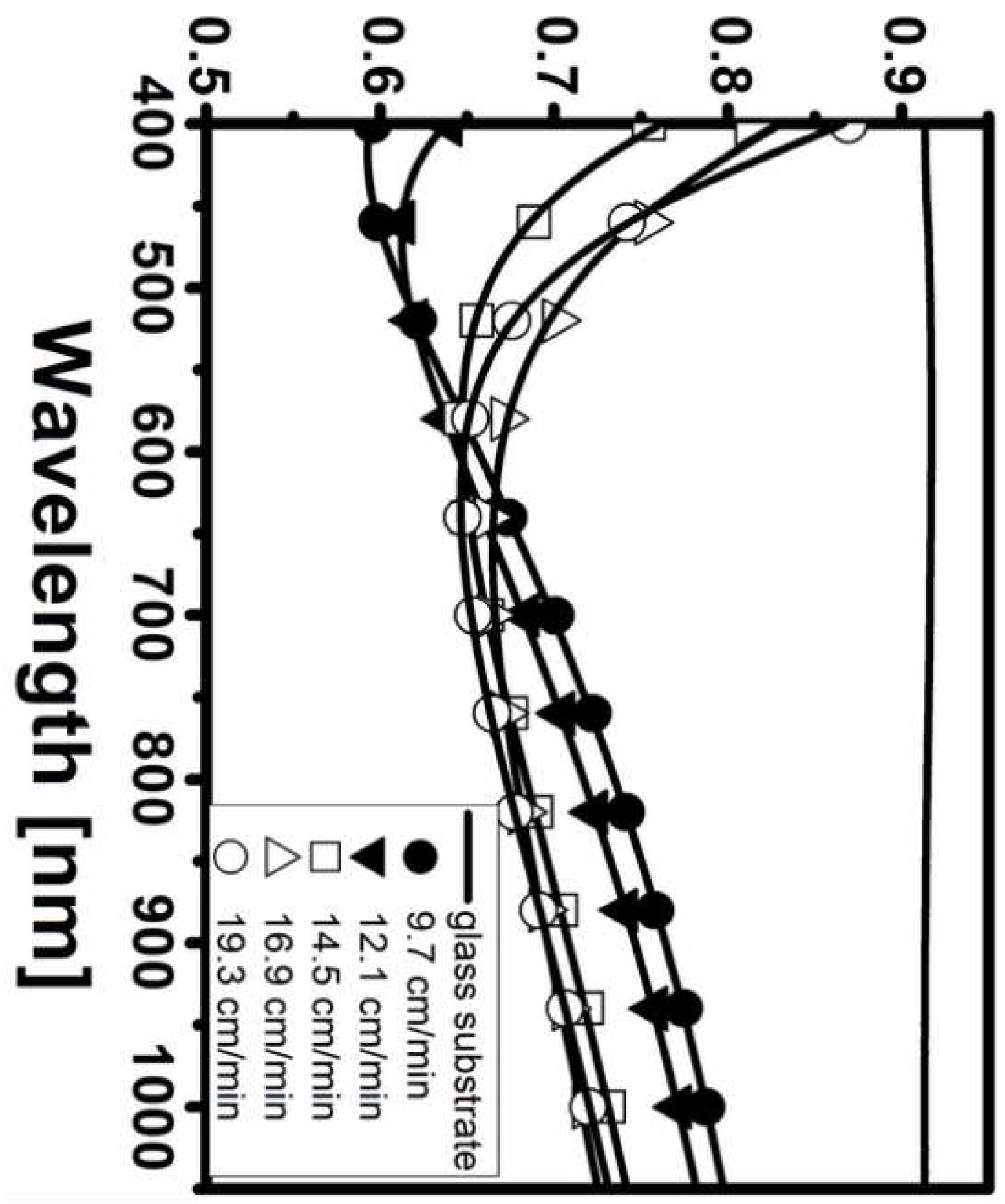




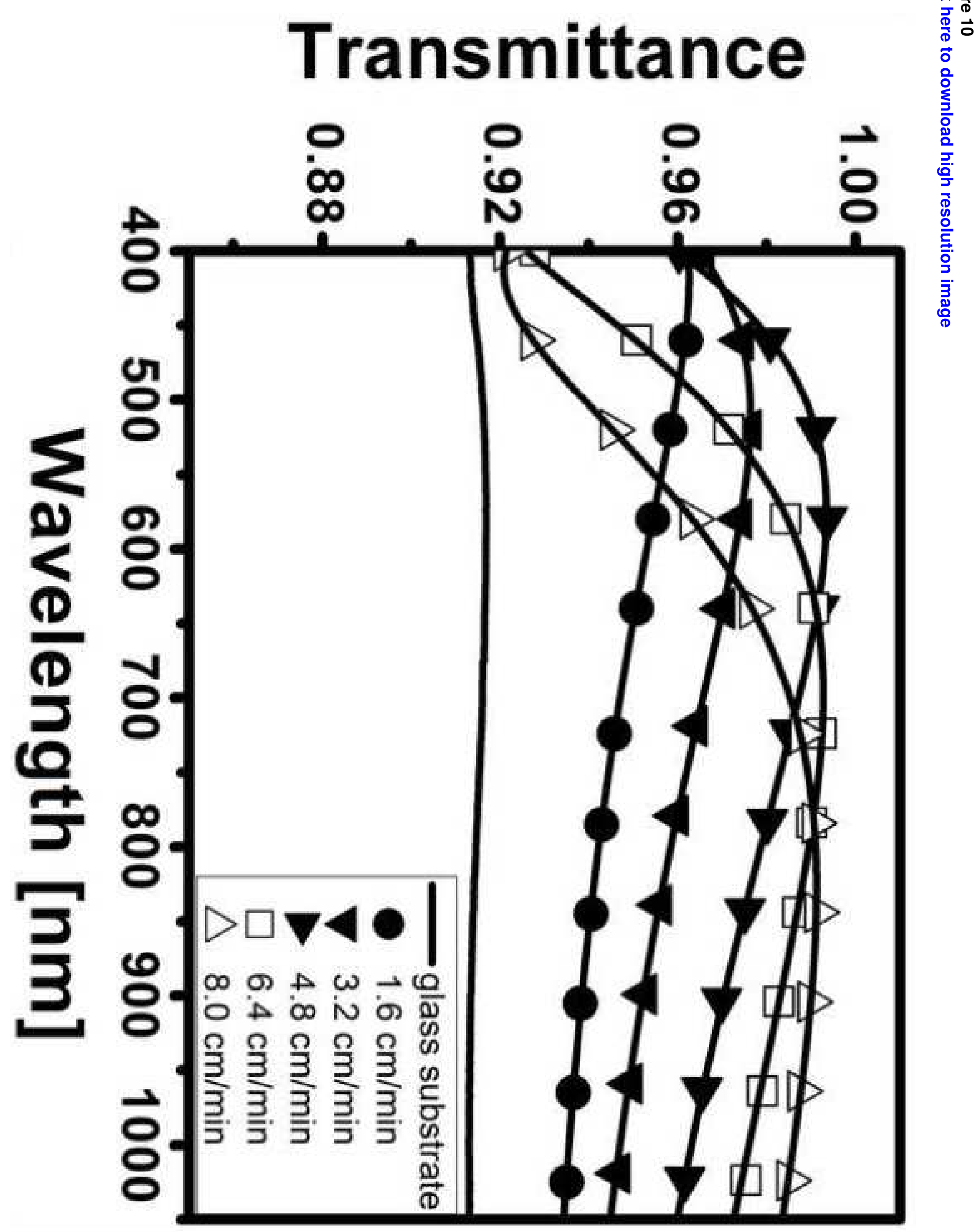




\section{Reflectance}

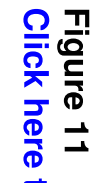

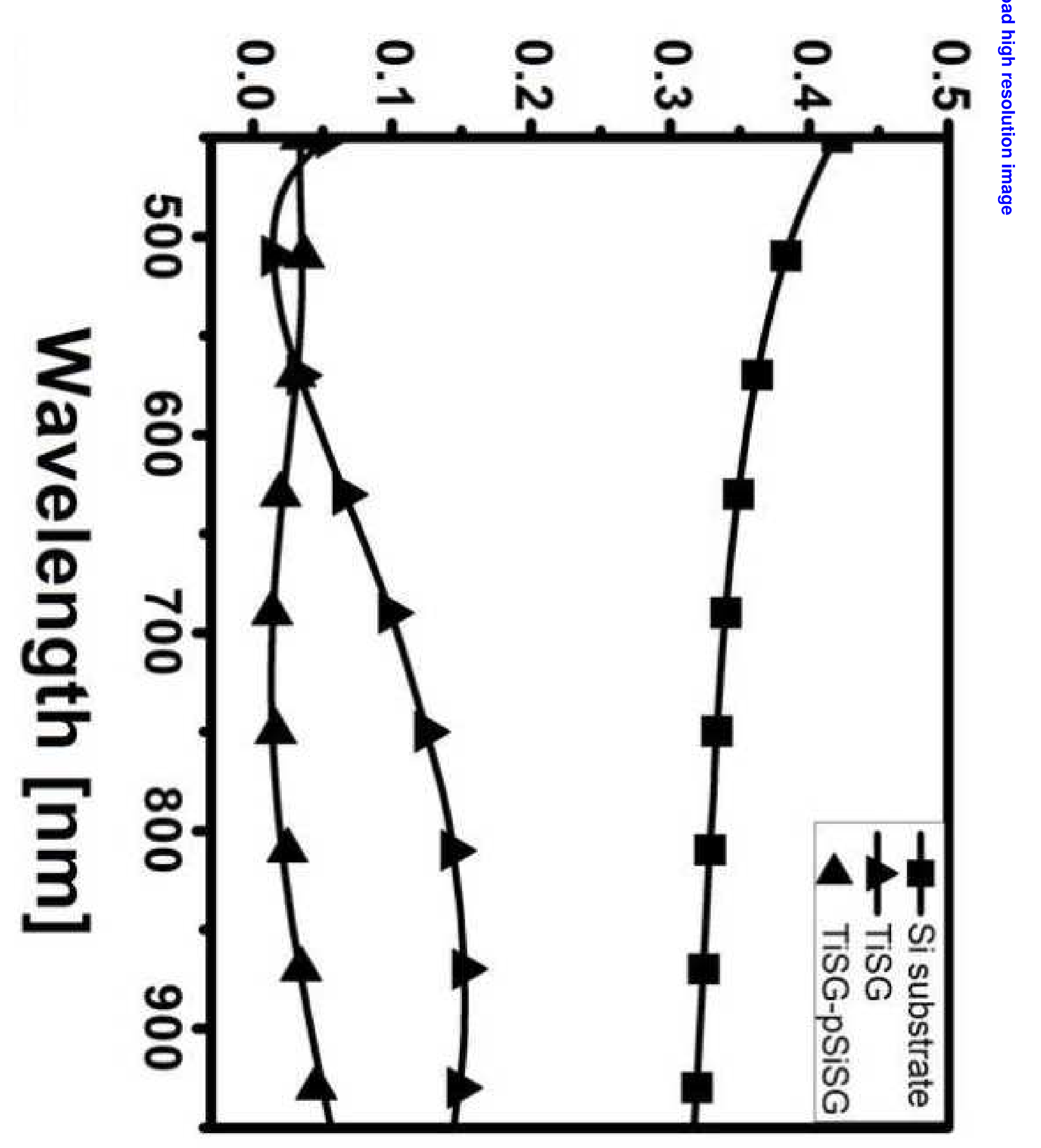




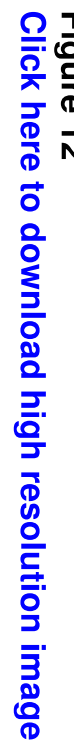




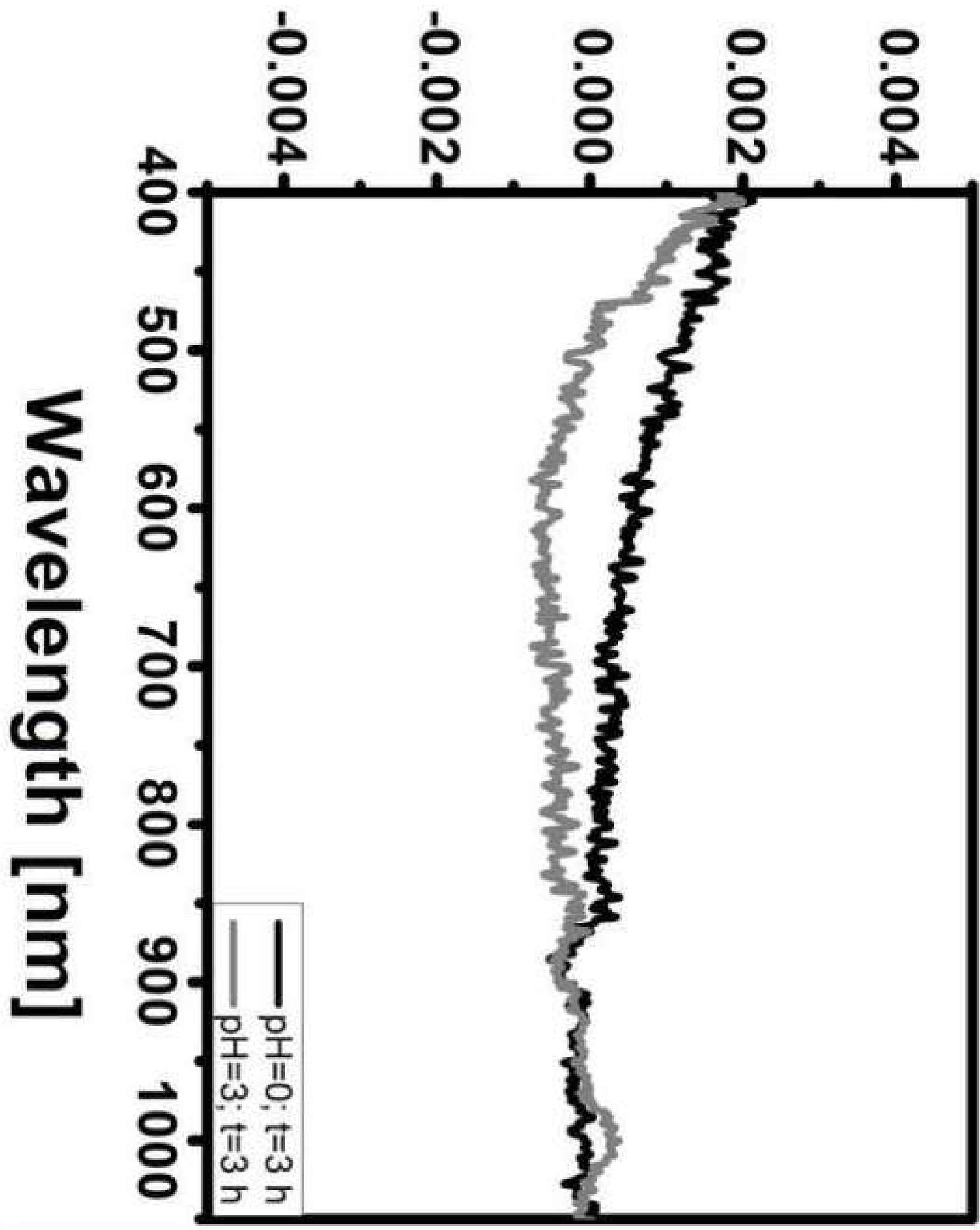




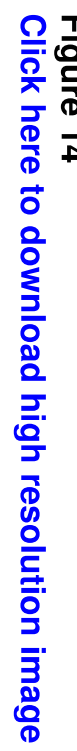




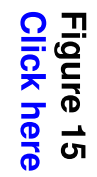

$$
\text { | }
$$$$
\text { ठ }
$$

응

క

。

등.

\&

을

흑

$\overline{3}$ 


\section{List of Figure Captions}

Fig. 1.: Simulated transmittance spectra of compact silica sol-gel film $(n=1.46, d=94 \mathrm{~nm})$, silica LB film $(\mathrm{n}=1.25, \mathrm{~d}=110 \mathrm{~nm})$ and their bilayer on glass substrate (spectrum of bare substrate was measured)

Fig. 2.: Schematic structure of prepared bilayered coatings (a: cSiSG-LB; b: TiSG-pSiSG)

Fig. 3.: Simulated reflectance spectra of titania $(n=2.00)$ and porous silica $(n=1.31)$ sol-gel bilayers on silicon substrate with various layer thicknesses

Fig. 4.: Simulated reflectance spectra of porous silica $(n=1.31, d=99 \mathrm{~nm})$ and titania $(n=2.00$, $\mathrm{d}=65 \mathrm{~nm}$ ) sol-gel films and their bilayer on silicon substrate

Fig. 5. Transmittance spectra of LB films of silica nanoparticles with different sizes after annealing at $450{ }^{\circ} \mathrm{C}$ (scattered points were measured and solid lines are the fitted curves)

Fig. 6. Transmittance spectra of compact silica sol-gel films prepared with different withdrawal speeds (scattered points were measured and solid lines are the fitted curves)

Fig. 7.: Layer thickness-withdrawal speed functions for different sol-gel films (titania, compact and porous silica)

Fig. 8. Measured and fitted transmittance spectra of cSiSG-LB type bilayered coatings on glass substrates (symbols are measured and solid lines are the fitted curves)

Fig. 9. Transmittance spectra of titania sol-gel films prepared with different withdrawal speeds (scattered points were measured and solid lines are the fitted curves)

Fig. 10. Transmittance spectra of porous silica sol-gel films prepared with different withdrawal speeds (scattered points were measured and solid lines are the fitted curves)

Fig. 11.: Reflectance spectra of TiSG-pSiSG bilayered coating on silicon substrate, titania sol-gel film and bare silicon substrate (in case of the bilayer symbols show the measured data and solid line is the fitted curve)

Fig. 12.: Photograph of a piece of silicon covered by TiSG-pSiSG bilayered antireflective coating placed on a virgin 3" silicon wafer

Fig. 13.: Difference of transmittance values for porous silica sol-gel films (pSiSG) caused by acidic treatment $(\mathrm{pH}=0$ or 3 ; duration: $3 \mathrm{~h}$ )

Fig. 14. Cross-section FESEM image of bilayer consists of a compact silica sol-gel film and a nanoparticulate silica LB film (cSiSG-LB; LB layer was prepared using $131 \mathrm{~nm}$ particles)

Fig. 15. Cross-section FESEM image of bilayer consists of titania and porous silica sol-gel films (TiSG-pSiSG) 